\title{
Dry stacking of high-grade flake graphite tailings: Tanzania
}

\author{
P Moshi Black Rock Mining Ltd, Tanzania \\ J DeVries Black Rock Mining Ltd, Australia \\ C Hogg CMW Geosciences Pty Ltd, Australia \\ C Lane Land \& Marine Geological Services Pty Ltd, Australia
}

\begin{abstract}
This paper presents some details of the feasibility study for a proposed dry stacked tailings management system for the Mahenge Graphite Project, in Tanzania. Black Rock Mining Limited is focused on developing its Mahenge Graphite Project, which holds the largest high-grade flake graphite resource reserve in Tanzania - the fourth largest graphite resource in the world. Several potential graphite processing operations are being proposed at various locations around the world and tailings management is a unique challenge given the geochemical characteristics of the graphite tailings and the topographical constraints of the site. Dry stacking of the graphite tailings offers a solution which minimises the environmental risks associated with conventional wet tailings and permits water reuse as part of the tailings management process. The project is located in a tropical savannah environment with a distinct difference between wet and dry seasons. Dry stacking offers a unique and innovative approach to minimising potentially large volumes of excess water during periods of high rainfall. At least $80 \%$ of the process water can be recycled.
\end{abstract}

Keywords: dry stacking, graphite tailings

\section{Introduction}

The Mahenge Graphite Project is located in the Ulanga district, Morogoro region of Tanzania, in East Africa. The project site is located $450 \mathrm{~km}$ by road from Tanzania's largest port, Dar es Salaam and is contained within $324 \mathrm{~km}^{2}$ of exploration tenements in the Ulanga district. Existing rail infrastructure is to be utilised during project development and operation. The project is located in a region with challenges ranging from sourcing qualified local manpower to upgrading existing road infrastructure and logistics to support the project. The project is in the definitive feasibility study phase with environmental approvals in process, and the next phase of engineering scheduled for early 2019. Figure 1 shows the location of the site and Figure 2 shows the layout of the of the proposed project infrastructure.

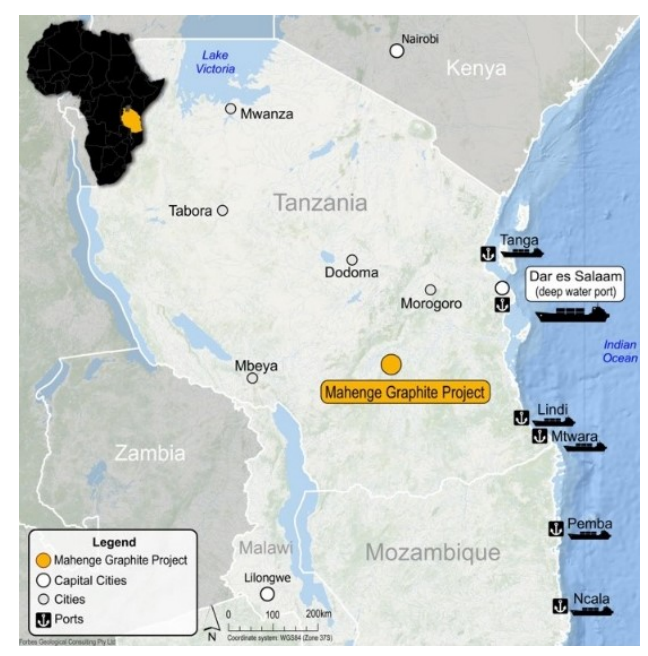

Figure 1 Project location 


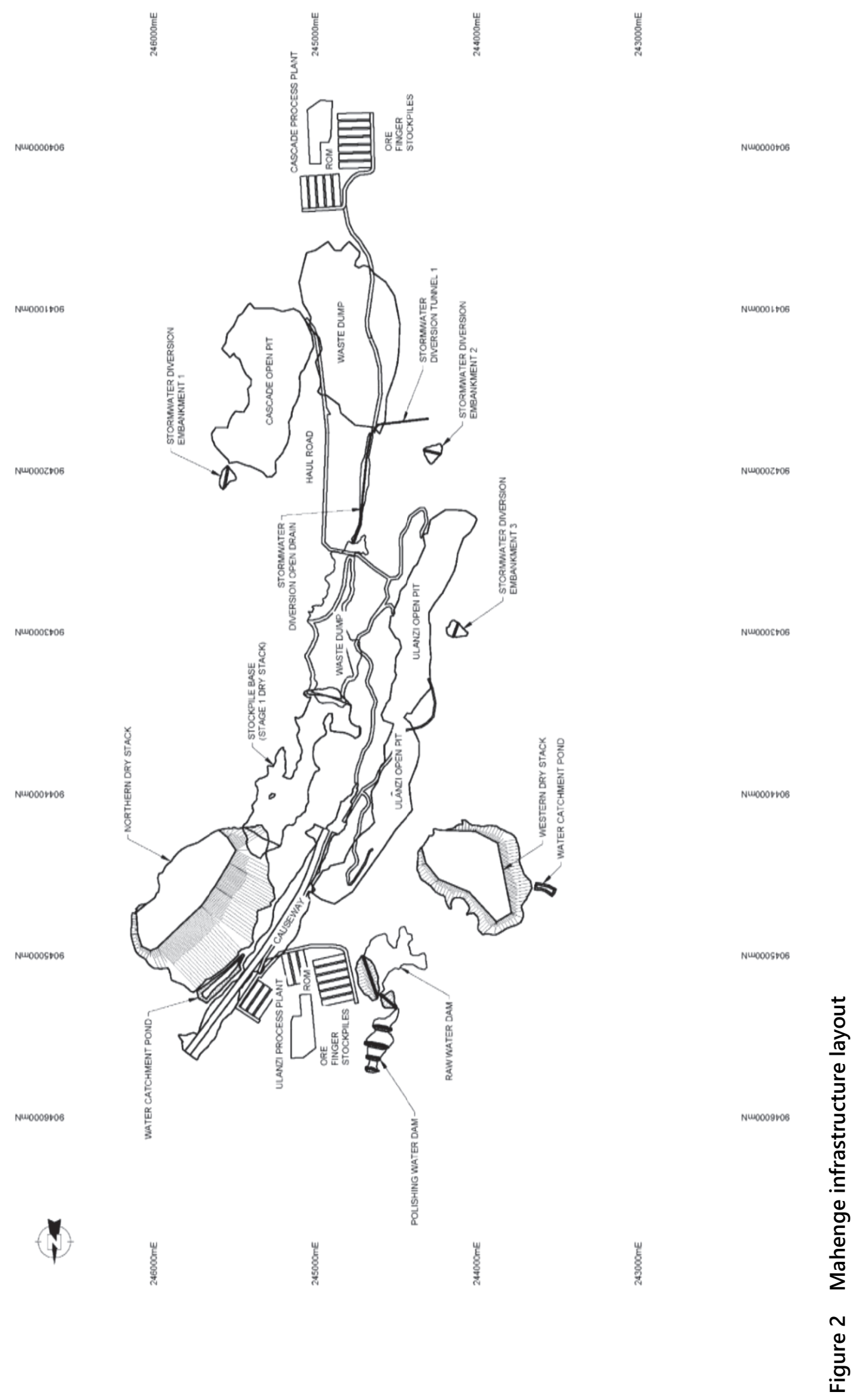


The project is owned and operated by an Australian publicly listed company, Black Rock Mining Limited through its Tanzanian representative company Mahenge Resources Limited.

The studies executed for the preparation of the concept designs for the dry stacked tailings for the project were prepared using the following Act and guideline:

- Tanzanian Regulations - Water Resources Management (Dam Safety) Regulations, GN 237, dated 2 August 2013 (United Republic of Tanzania 2013).

- Guidelines on Tailings Dams - Planning, Design, Construction, Operation and Closure (Australian National Committee on Large Dams 2012).

\subsection{Abbreviations}

The following abbreviations have been used in this paper.

Table 1 Abbreviations

\begin{tabular}{ll}
\hline Abbreviation & Definition \\
\hline AEP & Annual exceedance probability \\
ANCOLD & Australian National Committee on Large Dams \\
ATC & ATC Williams Pty Ltd \\
BGM & Bituminous geomembrane \\
BRM & Black Rock Mining Limited \\
CPC & CPC Project Design Pty Ltd \\
DCP & Dynamic cone penetrometer \\
DFS & Definitive feasibility study \\
DSTSF & Dry stacked tailings storage facility \\
ERT & Electrical resistivity tomography \\
g & Acceleration due to gravity \\
LDPE & Low-density polyethylene \\
LOM & Life-of-mine \\
NDSMRSF & Northern Dry Stacked Tailings Storage Facility \\
OMC & Optimum moisture content as a \% \\
PAF & Potentially acid forming \\
PAR & Population at risk (including employees) \\
PFS & Pre-feasibility study \\
SMDD & Standard maximum dry density \\
SPT & Standard penetration test \\
t/m ${ }^{3}$ & Density of soil or residue \\
TSF & Tailings storage facility \\
WDSMRSF & Western dry stacked tailings storage facility \\
\hline &
\end{tabular}




\section{$2 \quad$ Background}

\subsection{Climate}

The project area has a warm temperate climate with a wet season between November and May, and a drier period between June and October. Based on records from the Tanzania Meteorological Agency, Mahenge Meteorological Station, for the period 1961 to 2017, the average annual rainfall is 2,058 $\mathrm{mm}$ and the annual evaporation is approximately 1,300 to $1,400 \mathrm{~mm} /$ year.

\subsection{Topography}

The site is topographically challenging, as shown in Figure 3, with narrow valleys and steep slopes.

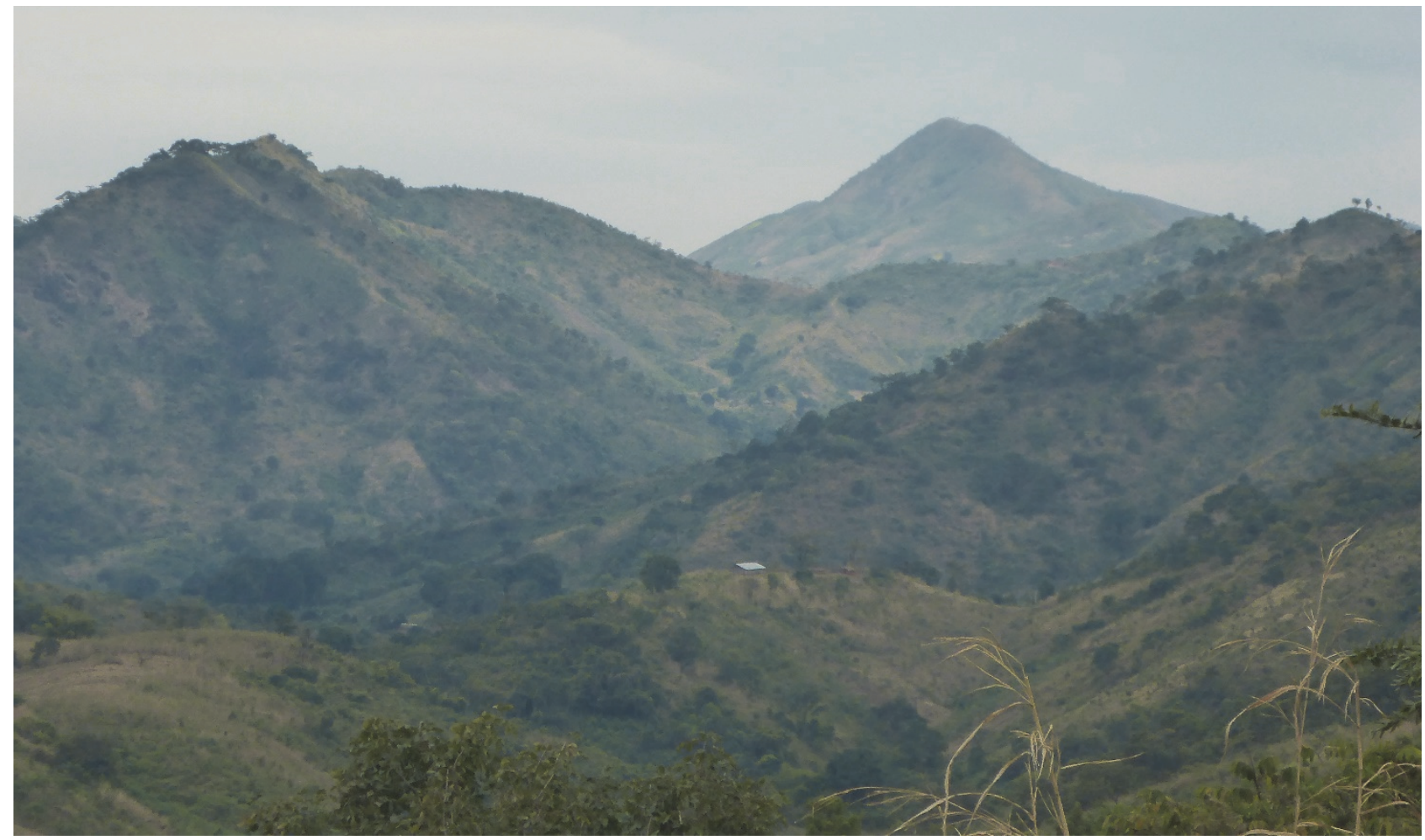

Figure 3 Typical topography of the project site

\subsection{Previous studies}

An initial PFS was completed in April 2017, and that work was subsequently optimised and signed off in August 2017. The optimised PFS required up to eight tailings dams over the life-of-mine. Such a footprint raised a significant number of economic, environmental and social risks for the project. As a result, a further review of the August 2017 PFS was undertaken, with a focus on the initial five years of mining operations.

This subsequent review in late 2017 and early 2018 tested a range of alternative approaches to the mine design and tailings management. The result was a significant change from the August 2017 PFS with the eight wet tailings dams replaced by the dewatering of process waste (tailings) and a single dry stack facility located close to the plant.

The reduction from eight tailings facilities to a dry stacked tailings facility resulted in a significantly reduced water management risk and infrastructure requirements but most significantly resulted in a development footprint that contains the operations within one valley between Ulanzi and Cascades deposits. This design underwent a risk assessment process in April 2018 which confirmed the tailings dewatering and dry stacking as the preferred approach to tailings management. 


\subsection{Dry stacking}

To enable dry stacking to be executed tailings is typically thickened to a slurry density of $65-70 \%$ solids by weight before being filtered to $80-90 \%$ solids by weight to further reduce the volume of liquor placed into the dry stack. The filtered tailings is then transported by conveyor or truck and then placed, spread and compacted to form an unsaturated, dense and stable tailings stack; hence the terminology 'dry stacked tailings'. The recovered water is recycled for reuse in the processing operations.

Dry stacking of tailings has been used where:

- Water conservation and reuse is vital. For example, Jabil Sayid in Saudi Arabia, Skorpion Zinc Mine in Namibia, La Copia Mine in Chile and Alamo Dorado in Mexico.

- Seismicity of the site is such that the tailings need to be dewatered as much as possible to minimise the potential for liquefaction and maintain the stability of the storage facility. For example, La Copia in El Peñon and Can Mines in Chile.

- It is environmentally advantageous to do so. For example, in cold climates (arctic and subarctic) where freezing of the tailings slurry and supernatant water in the water pond makes the components of the slurry (solids and liquids) very difficult to handle, examples are the Greens Creek and Pogo Mines in Alaska and Raglan Mine in Quebec.

- Improved stability and storage capacity where required, for example Cupias Tailings Dam near Tayoltita in Durango State, Western Mexico, La Herradura near Caborca Sonora, in northwestern Mexico and El Indio in Chile.

- Improved handling is required such that the tailings can be mixed with mine waste.

- There is limited land for storage and the tailings have to be mixed with mine waste.

Filtering concentrates is very common in a range of climatic regimes. However, most filtering is performed in climate-controlled conditions, primarily covered areas, where the impact of direct rainfall is excluded from the whole filtering process and associated operations.

The key drivers for the dry stacking at the Mahenge Project are:

- Reduction in water demand. There is significant surface water flow during the wet season which quickly runs off and the locals are reliant on the remaining surface water during the dry season to sustain their local agriculture. Dry stacking allows for up to $80 \%$ of the process water to be recovered for reuse.

- Seismicity. The Mahenge Project is in a medium to high seismicity zone.

- The topography is vertically challenging and the studies of the wet tailings options demonstrated that the volumes of earthworks required were significant with very high embankment volume to storage volume ratios, which not only resulted in high construction costs but multiple facilities were required to achieve the LOM tailings storage requirements.

- Earthwork construction costs, as there is no mine waste for embankment construction works and the likely alternative is upstream construction using compacted dried tailings.

- The LOM TSF footprint of the dry stacking option is significantly less than the alternative wet storage options.

- LOM capital and operational expenditure are significantly less than the alternative wet storage options.

- Risk in terms of TSF stability. Not only does dry stacking allow for the elimination of water from the TSF, but the consequences of failure in terms of dam break are significantly reduced.

- The closure liability is significantly less than the alternative wet storage options. 


\section{Methodology}

At this stage the conceptual designs for the project are at a feasibility study level. The study was executed based on desk study of available information, limited geotechnical data for the site, a geotechnical testing program for the oxide tailings, a geochemical assessment and a preliminary hydrology assessment of the project area.

\subsection{Seismicity}

The seismicity of the Mahenge project area was assessed using a literature review.

A seismic coefficient of $0.2 \mathrm{~g}$ (return period 500 years) was assumed in a previous study of the wet tailings option based on the worldwide seismic hazard map.

A review of Lubkowski et al. (2014) provided more detailed information of seismic zones within Tanzania. There are seismic zones on the coast around Dar es Salaam, in the interior and a high seismicity zone in the north of the country. The Mahenge Project area is between these seismic zones.

For the purposes of this study it was assumed that the Mahenge Project area had similar seismicity to Dar es Salaam. Lubkowski et al. (2014) provided estimated peak ground accelerations as follows:

- $0.09 \mathrm{~g}, 1: 475$ year AEP.

- $0.20 \mathrm{~g}, 1: 2,475$ year AEP.

For the purposes of this study the maximum design earthquake (MDE) of 1:1,000 years AEP, has been assumed to be $0.2 \mathrm{~g}$. This is believed to be a conservative assumption and further work is required to confirm the seismicity of the Mahenge project area.

\subsection{Geology}

The geology of Tanzania describes Mahenge and the surrounding areas to be located within Neoproterozoic gneiss, migmatite, high-grade mafic and felsic granulite, which are inter-bedded with amphibolites, marble quartzites, schist and mylonite. Considering the regional metamorphism processes, Mahenge falls on the Usagaran belt which is composed of well-foliated gneisses. These are a result of semi-pelitic, politic and calcareous sediments with some intrusions of ultra-basic igneous rocks. Due to intense regional metamorphism all the rocks have undergone complete recrystallisation. One example is the formation of dolomitic limestone. The crystalline limestone group of Mahenge is underlain by a banded series of hornblende gneiss, biotite gneiss, and quartzo-feldspathic gneiss. Garnet is a common accessory mineral.

\subsection{Geotechnical site investigations}

Preliminary geotechnical site investigations for the original wet tailings storage options for the project comprised drilling of two cable percussion boreholes per selected site for the purpose of assessing the subsoil strata, carrying out in situ SPT and extracting soil samples for laboratory tests and analysis for design of the proposed structures.

The geotechnical borehole investigations were mainly executed in the base of the valleys and indicated that the subsoil profile within the project site down to $10 \mathrm{~m}$ depth can be characterised as comprising of layers of alluvial materials. Very loose silty sand of high plasticity up to $3.3 \mathrm{~m}$ depth typically overlies medium dense clayey sand of intermediate plasticity up to $4.5 \mathrm{~m}$ depth which is in turn followed by intermediate plasticity medium dense to very dense silty sand with rock encountered between 5.95 and $10.0 \mathrm{~m}$ below ground level. Groundwater was encountered at between 1.0 to $2.0 \mathrm{~m}$ below ground level.

This geotechnical work was supplemented with ERT to gain a better understanding of the subsurface profile. A total of 11 ERT profiles were carried out in the study area using an ARES Terrameter (resistivity meter) (http://www.gfinstruments.cz) which confirmed a variable weathered formation to a depth of $15 \mathrm{~m}$ with hard rock below this depth. 
At the site of the proposed NDSMRSF DCP tests were executed. These tests indicated that there is a soft layer of clay/silty/clayey sands extending from ground level down to $1.9 \mathrm{~m}$, especially in the low-lying areas near the base of the proposed dry stack and raw water/polishing dams with hard clay at depth. The consistency of the foundation soil generally increases to stiff to very stiff up the sides of the valleys.

\subsection{Geotechnical testing of tailings}

Testing of the tailings was executed by Golder in Burnaby BC, Canada. The sample supplied comprised oxide ore tailings. Primary tailings is yet to be tested.

The initial sample of graphite tailings prior to shear box testing averaged $62 \%$ sand and $38 \%$ fines, (silt and clay fraction). The tailings is non-plastic with a soil particle density (specific gravity) of 2.55. The SMDD of the tailings was $1.77 \mathrm{t} / \mathrm{m}^{3}$ at an OMC of $13.5 \%$. The particle size distribution curve is shown in Figure 4.

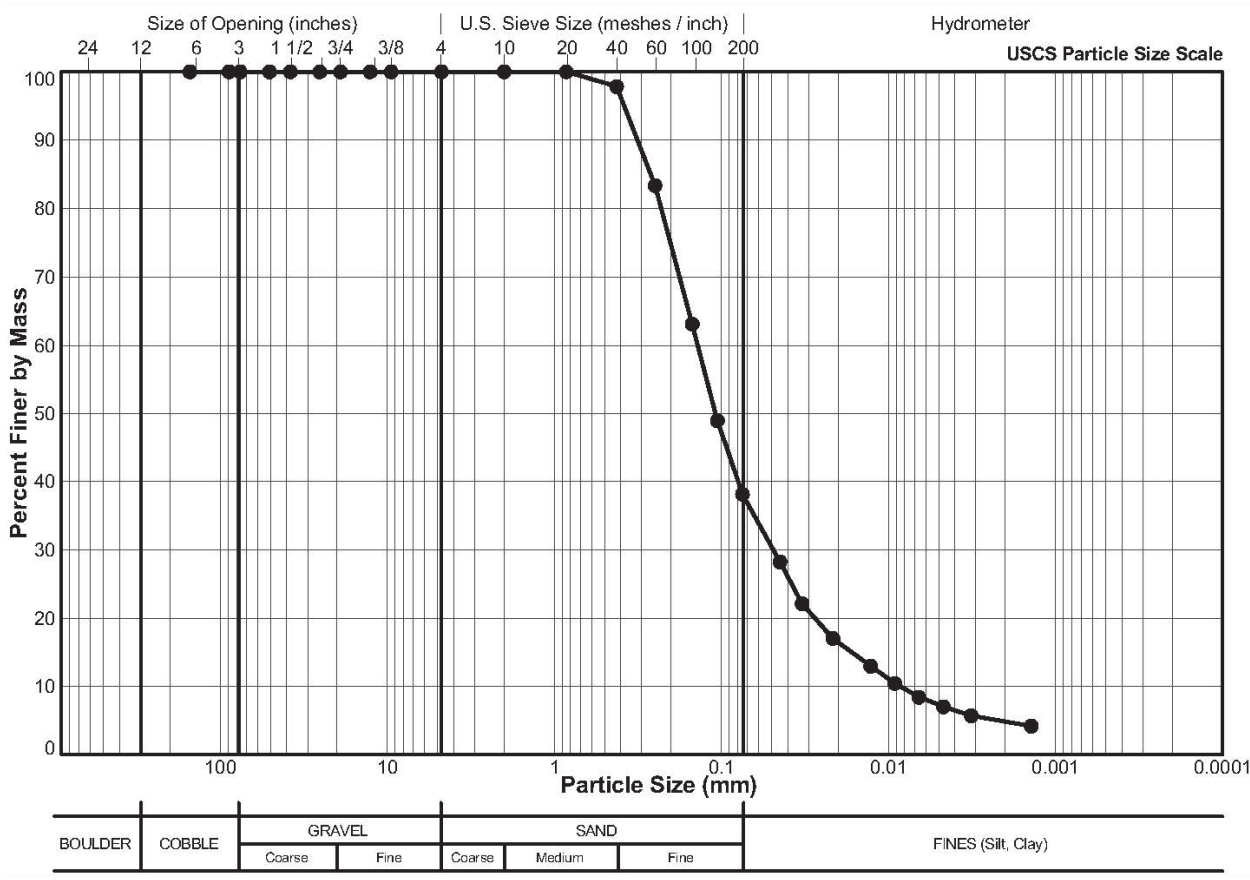

Figure 4 Oxide tailings particle size distribution

Shear box testing was performed on samples of tailings remoulded to 88,92 and $96 \%$ of SMDD at OMC. The results of the shear box tests ranged from an angle of internal friction of $37^{\circ}$ and $41^{\circ}$. The lower bound shear strength was subsequently adopted in stability analyses.

Laboratory hydraulic conductivity tests were conducted on samples of tailings remoulded to 88 and $96 \%$ of SMDD at OMC. The results indicated relatively low permeabilities (in accordance with Terzarghi \& Peck 1967) of between $6 \times 10^{-6}$ and $3 \times 10^{-6} \mathrm{~m} / \mathrm{s}$ (lower permeability recorded for samples remoulded to a greater density). However, the tailings will have a higher permeability than say a typical gold tailings, of $10^{-7}$ to $10^{-9} \mathrm{~m} / \mathrm{s}$.

The engineering properties of the tailings are summarised below:

Stacked density:

Specific gravity:

Angle of internal friction:

Particle size distribution:

Hydraulic conductivity:
$1.7 \mathrm{t} / \mathrm{m}^{3}$ (dry)

Approximately 2.65

$37^{\circ}$ (based on shear box testing)

$38.1 \%$ passing $75 \mu \mathrm{m}$

$3.0 \times 10^{-6} \mathrm{~m} / \mathrm{s}$ 


\subsection{Geochemical assessment}

A geochemical characterisation of the tailings was performed by Graeme Campbell \& Associates (GC\&A) in 2018. The results of the geochemical characterisation indicated that:

- The tailings is PAF - low capacity, due to a pyrite-S value of $0.1 \%$ and an acid neutralisation capacity (ANC) value less than $1 \mathrm{~kg} \mathrm{H}_{2} \mathrm{SO}_{4}$ /tonne.

- The capillary water initially reporting to the DSTSFs should be circumneutral $(\mathrm{pH} \mathrm{6-8)} \mathrm{with} \mathrm{a}$ chemistry of no concern environmentally.

- In an unsaturated, but still moist state, the 'trace-pyrite' in the dry stack profile should be reactive enough for the 'capillary-water' to swiftly develop $\mathrm{pH}$ values of 4-5 with concentration of soluble-metals (e.g. $\mathrm{Fe}, \mathrm{Al}, \mathrm{Mn}$, and $\mathrm{Ni}$ ) within the $\mathrm{mg} / \mathrm{L}$ range at least.

- This assessment has implications for closure of the DSTSFs. GC\&A concluded that the DSTSFs would need to ensure geochemical control for the DSTSF during both operations, and post-closure.

- Partial cementation was indicated in the oxide tailings during the initial weathering (kinetic) testing program. This kinetic testing program is still underway.

For the purposes of the design of DSTSFs it has been assumed that it will store PAF tailings.

For the purposes of the operation, to minimise the impact of surface water entering the DSTSF, the design of the DSTSFs is based around:

- Providing protection and drainage systems to minimise entry of water into the stack.

- Providing a base drainage system to collect any internal leachate infiltrating through the stack.

\subsection{Hydrology}

There is limited data on rainfall intensity. However, based on daily records for 2015-2017, the maximum rainfall recorded in one day was 103, 121 and $140 \mathrm{~mm}$ respectively.

Rainfall events at Mahenge are typically of short duration with a high intensity. Whilst the tailings has a significant sand fraction, the rate at which rainfall soaks into the exposed tailings stack is limited since the rainfall intensity far exceeds the permeability of the stacked compacted tailings. Most of the incident rainfall, therefore, runs off the surface provided that ponding is not permitted (i.e. surfaces are graded). A small percentage of rainfall will likely infiltrate into the stack. The net infiltration rate will have to be assessed in greater detail in the next stages of the project to fine tune the design of the drainage and seepage collection that must be incorporated into the stack. High intensity events have the potential to generate runoff and erosion. Anecdotal evidence suggests that the nature of the rainfall events limits the periods of disruption. Stacking operations may, however, be disrupted for short durations, generally of less than three hours, on a one to three day basis during the wet season.

Hydraulic design has been based on precipitation of $150 \mathrm{~mm} /$ day with the bulk of this rain occurring over a three hour period. This has been assumed to be a rainfall event of medium probability (nominally 1:10 year AEP).

\section{$4 \quad$ Dry stack tailings storage facility design}

The design objectives of the DSTSFs (northern and western) are:

- Maximise the storage of tailings within a restricted footprint area. Studies were carried out to examine storage capacity at selected sites, stack geometry and the optimisation of the project layout which had to incorporate various infrastructure.

- Provide adequate stack stability. Studies were conducted to examine stack geometry, various slope reinforcement methods and stack drainage. 
- Reducing environmental impact due to seepage. A BGM is incorporated into the base of the dry stack to contain any potential leachate which could migrate to the base of the stack. Various drainage features are incorporated into the design of the DSTSF to segregate clean and potentially contaminated runoff.

\subsection{Hazard rating}

In accordance with the criteria for categorisation of dams, according to the Tanzanian Water Resources Management (Dam Safety) Regulations (United Republic of Tanzania 2013), the proposed dry stacking of the tailings can be categorised as low ' $C$ ' based on considerations for:

- Loss of life.

- Economic and social loss.

- Environmental and cultural loss.

Based on ANCOLD (2012) as far as this document relates to dry stacks, the level of severity rating is considered to be medium, and consequence rating for the proposed DSTSFs has been assessed as 'significant', based on a PAR of $>1$ to 10 (i.e. operators on or about the stack).

A major failure of the dry stack should have little impact and would be contained within the mine lease since dry stacking significantly reduces the volume of water contained within the stack and thus the potential for solids to liquefy with a failure significantly reduced. The consequences of failure in terms of discharge to the environment in the event of a dam break are significantly reduced.

\subsection{Operation and design considerations}

The proposed method of tailings storage is by stacking of dewatered tailings to form a side-hill free standing structure. The tailings will be delivered to the storage area by a truck operation. The tailings will have a maximum moisture content not exceeding $20 \%$. There are two areas proposed for dry stacking (refer back to Figure 2). The NDSMRSF, which will be commissioned first, with the tailings initially being placed in the southern section of the NDSMRSF and covered by low grade ore stockpiles. Stacking will continue to the north and the NDSMRSF have a life of approximately 24.5 years. The WDSMRSF will be commissioned later in the project life and store the final 5.5 years of tailings production.

The two DSTSFs will accommodate approximately $76.5 \mathrm{Mt}$ of tailings at an in situ dry density of $1.7 \mathrm{t} / \mathrm{m}^{3}$. The NDSMRSF will have a maximum height of $140 \mathrm{~m}$. Stacking rates will vary according to the operational requirements. Assuming continuous operation of $8,000 \mathrm{hrs}$ per annum, the average stacking rate would be approximately $319 \mathrm{t} / \mathrm{hr}$.

The dewatered tailings will initially be placed at the southern end of the NDSMRSF, on an area lined with a $\mathrm{BGM}$. The base of the lined portion of the facility will incorporate an underdrainage layer of quarried gravel and rock. The base of the stack will slope towards downstream water ponds such that leachate will flow under gravity to the ponds. Rainfall runoff falling on the top of the stack will flow via internal finger drains under the storage facility, down the side of the stack to an underdrain (Figure 5). Rainfall falling on the stack batters will also be diverted to the downstream pond. Drains will be cut into the sides of the valley as the DSTSF rises to divert runoff away from the stack (Figure 5). 


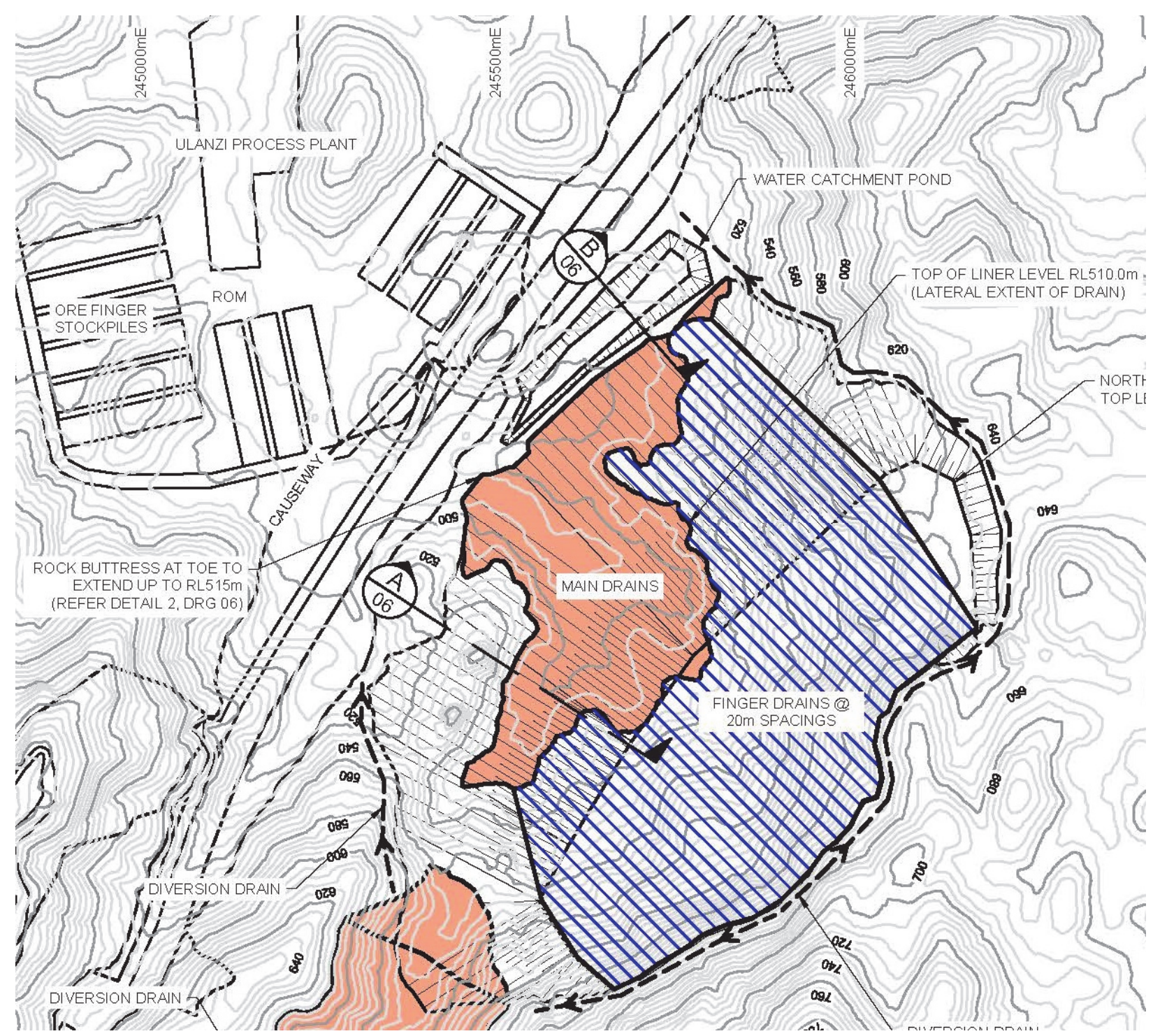

Figure 5 Typical dry stack layout - NDSMRSF shown, WDMRSF has similar concept

The tailings deposit will be built in a series of terraces. The proposed bench height is $5 \mathrm{~m}$. An outer perimeter of oxide tailings will be placed in advance of each lift. The tailings will be compacted in order to achieve the design dry density. Use of an impact roller is being considered to increase the compacted layer thickness. The exposed final slopes of the stack will be covered with geotextile, mine waste, soil and mulch forming. This is important as capping of the stack slopes after the final height is reached will not be possible due to the steep geometry of the stack.

The tailings are relatively permeable and hence development of a phreatic surface within the stack was seen as a potential issue. In order to manage the phreatic surface in the stack, the following processes will be incorporated into the construction of the DSTSF:

- Sloping of the top surface stack at less than $0.5 \%$ to internal drains (to avoid discharge over outer slopes).

- Internal finger drains down the sides of the valley and interface with the stack linked into the underdrain at the base of the facility.

- Underdrains located beneath the DSTSFs footprints are designed to accept water emanating from the finger drains. 
- During the wet season the tailings will be placed and compacted and temporary covers, such as LDPE, may be deployed as part of operations to shed water from the surface and limit vertical infiltration. Some internal drainage such as drain-coil or similar would need to be placed over the LDPE within the stack for every $5 \mathrm{~m}$ lift at $20 \mathrm{~m}$ intervals to intersect water ingress into the stack as required as part of operations.

During the wet season stacking operations will need to be confined to smaller working areas and may need to cease for short periods during storm events. An emergency stacking location is provided for these events. When operations cease during storm events, stacking can resume after the storms once the stack area has been assessed by site geotechnical personnel.

The design concept of the DSTSFs drainage system beneath the footprint is presented in Figure 6.

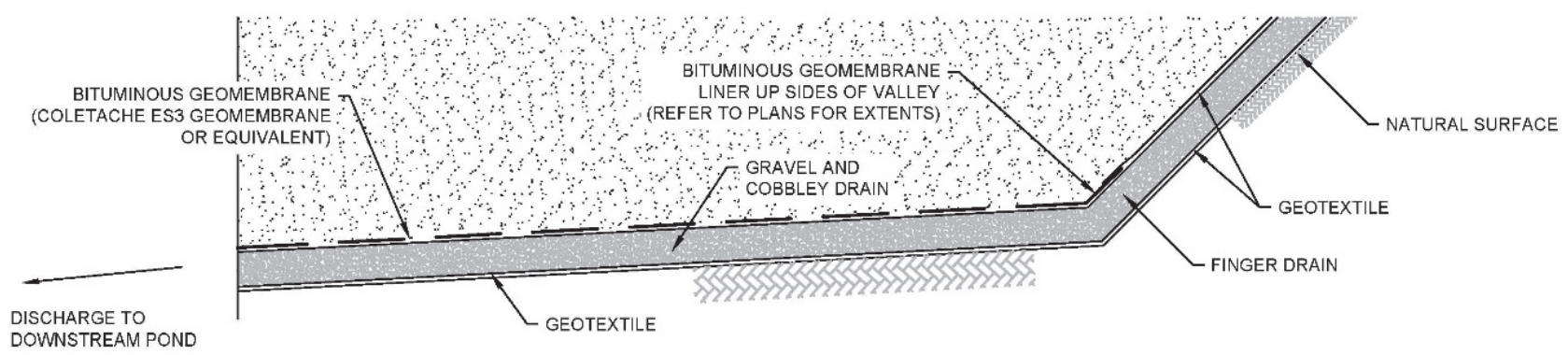

$\frac{\text { MAIN UNDERDRAIN - TYPICAL SECTION }}{1.20}$

Figure 6 Typical dry stack drainage concept

\subsection{Design geometry}

The dry stack geometry will have slopes of $1(\mathrm{~V}): 2.5(\mathrm{H})$. Stability analyses have been performed to confirm overall stack stability and define the operating criteria which will constrain the stacking. Figure 7 shows typical dry stack geometry.

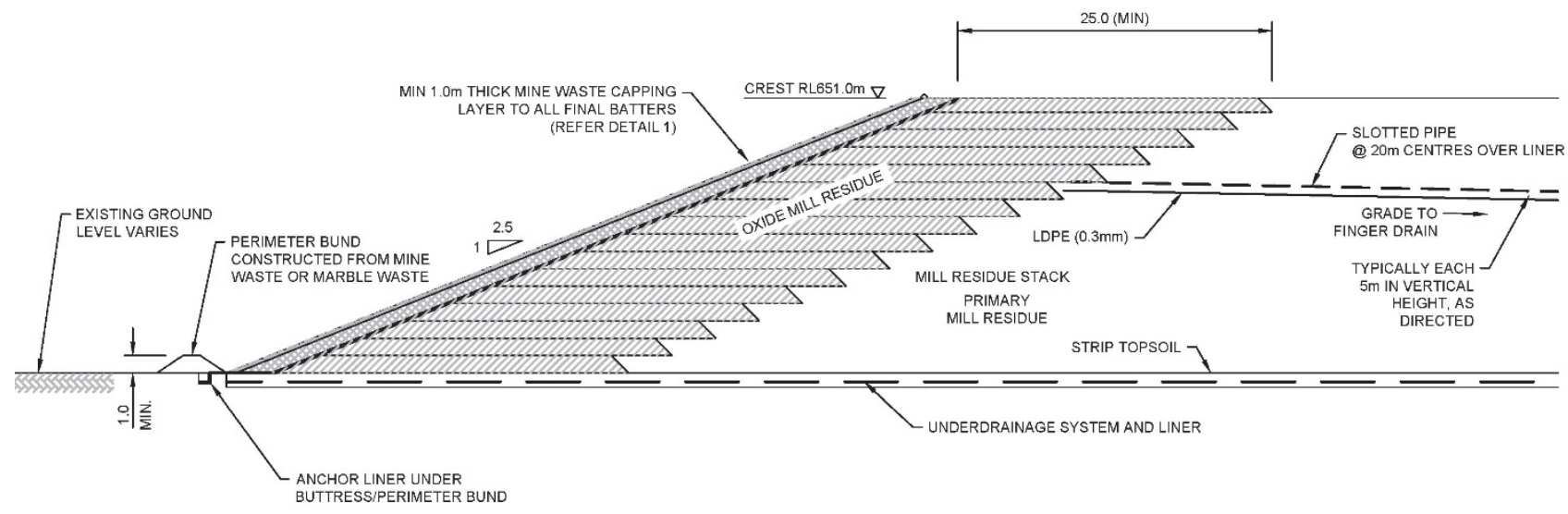

A DRY STACK BATTER - TYPICAL SECTION
03 NTS

Figure 7 Typical dry stack geometry

Studies conducted indicated that the slope could be steepened using slope reinforcement (i.e. cement stabilisation or soil reinforcement). However, these methods are expensive. The steeper outer slopes and lower final height of the stacks had increased unit costs, in terms of cost per tonne of tailings stored, and were not considered to be beneficial for the project when traded-off against the reduction in liner area and drainage works. 
Stack geometry can potentially be further optimised by in the future during initial operations when actual data on tailings properties will be available. The potential optimisation may include steepening of tailings slopes or increasing the overall stack height. However, the control of the phreatic surface within the stack will be critical to slope design; internal liners with slotted pipe drainage could assist with management of the phreatic surface.

\subsection{Water management system}

Surface water will be removed from the DSTSFs by internal finger drains which run down the side of the stack, at the interface with the natural ground and link with the main underdrain in the base of the stack. This underdrainage system will deliver water under gravity to an external water pond downstream of each DSTSF. Water collected in the downstream pond can be pumped to the water dam near the plant and be used in ore processing.

Water that falls on the stack slopes will be diverted to the downstream water ponds.

Runoff from up-slope of the stack, where practical, will be diverted around the downstream ponds and discharged downstream.

The downstream ponds have been sized based on $150 \mathrm{~mm}$ of precipitation on the catchment area. A runoff coefficient of 0.5 has been used. The NDSMRSF downstream water pond will have an operating volume of $40,000 \mathrm{~m}^{3}$ and the WDSMRSF downstream water pond will have an operating volume of $25,000 \mathrm{~m}^{3}$.

\subsection{Construction methods}

In preparation for the placement of tailings in the DSTSFs, the following works will be executed:

- The vegetation will be removed from the DSTSF footprints and mulched for redeployment. The existing topsoil and arable subsoil will be removed to stockpiles and/or to create suitable agricultural areas.

- The surface will be prepared to facilitate construction of the drains beneath the BGM and its placement. The extent of the lined area will be sufficient for two years of operation with a maximum stack height of $5 \mathrm{~m}$. The liner will be anchored under containment bunds (Figure 7).

- Containment bunds around the perimeter of the stack area will be constructed to contain spills. The fall on the liner should not be less than $0.5 \%$. This approach will allow for the development of stacking techniques and allow for a period of trials during commissioning and progression to full plant start-up.

- A drainage system will be placed on the BGM to collect any leachate from the stack. This drainage will be joined to a water pond downstream of the stack to facilitate sediment collection and water quality sampling.

- An internal finger drainage system will be placed along the interface between the stack and the natural ground surface. This drainage system will facilitate the collection of runoff from the compacted top surface and internal drainage, such as the drain-coil or similar, from the stack. The internal finger drains will connect with the drainage system under the stack (Figure 6).

- The materials forming the drainage layers will comprise quarried marble. The drainage layers will also include a geotextile to prevent blockage with fines.

- The development of stack areas perimeter bund will be constructed from mine waste or the weathered marble.

- Contour drains will be cut into the hills surrounding the stack which form part of the containment, in order to divert runoff around the stack. 
- As the stack height increases, the sides of the hills forming the containment will be stripped of vegetation, topsoil and arable subsoil. The vegetation will be mulched and together the soils redeployed on the outer face of the DSTSF to avoid stockpiling where possible.

- As the stack height increases, the exposed outer slopes of the stack will be capped by a geotextile, beneath mine waste/slightly weathered to fresh marble and soils removed from the stripping and mulch (Figure 8). This operation will be conducted for each $5 \mathrm{~m}$ lift in stack height.

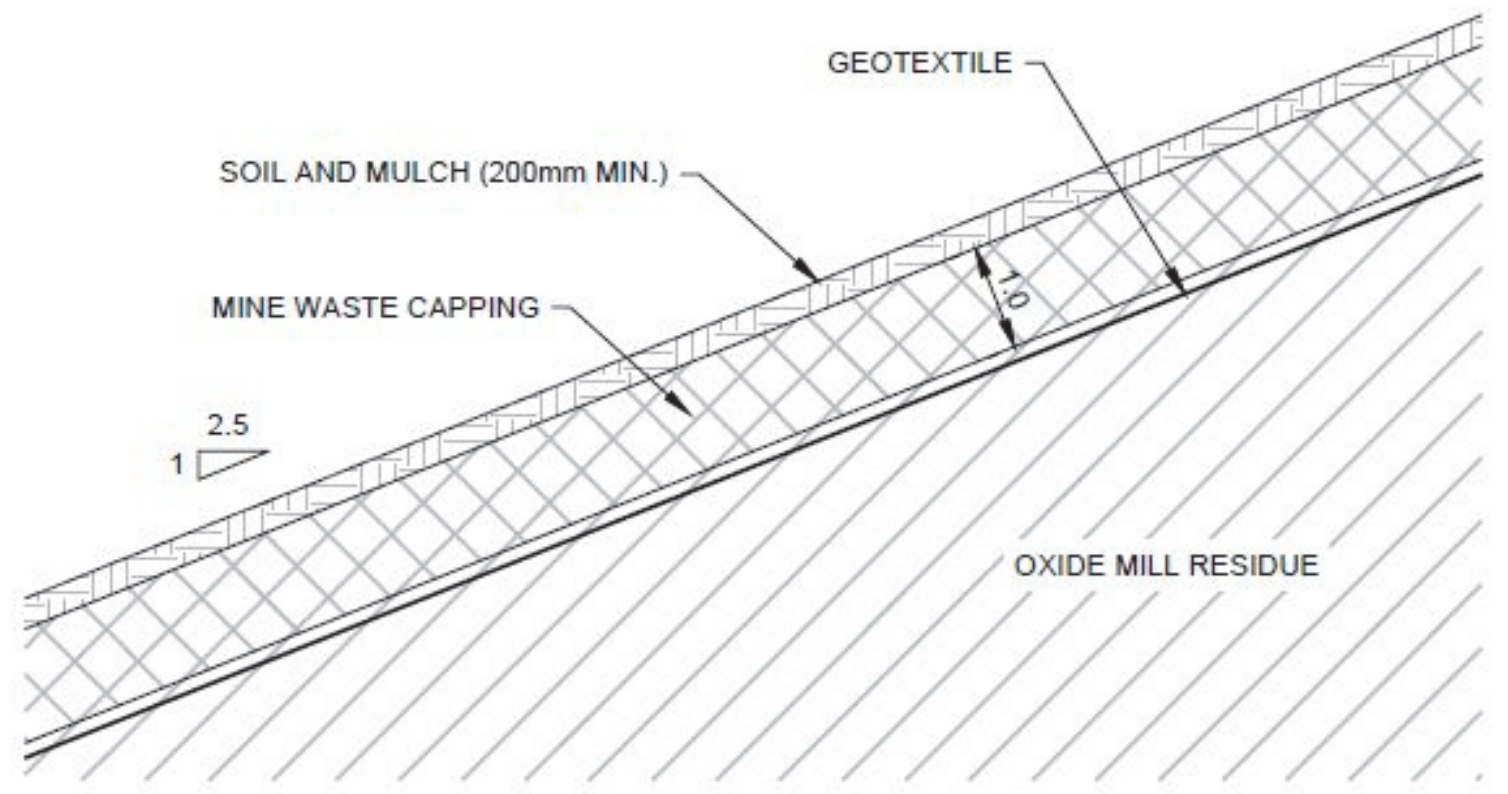

Figure 8 Typical dry stack batter rehabilitation concept

\subsection{Dust management}

Dust generation will be minimal since the moisture content of the filtered tailings at the time of deposition is expected to be $20 \%$ by mass (mass of liquids divided by mass of solids). Spray irrigation, with or without organic stabilising compounds, can be applied as required and the stack will be covered with mine waste once the design height in any lift section is reached. In the medium to long term, progressive placement of geotextile, mine waste, soil and mulch will form the permanent capping to prevent dust generation.

Provision for the TSF construction works will include a water cart on location to provide dust suppression as required. This control measure will prevent dust becoming airborne and subsequently being mobilised into the surrounding environment, and becoming a visibility issue, or becoming a respiratory hazard for construction personnel.

\subsection{Instrumentation and monitoring}

Installation of piezometers and survey prisms will be included in the final stack design. Vibrating wire piezometers should be installed within the DSTSF foundations and at several locations within the operating stack in order to monitor the phreatic surface within the stack. Survey prisms should be installed on the outer slopes of the stack (i.e. following capping of the slopes) in order to monitor stack movement. This monitoring will allow ongoing assessment of stack stability.

Groundwater monitoring bores will be established within the project area and in particular, downstream of the DSTSFs, as recommended by the project hydrogeologist. The DSTSF monitoring bores should be included in a site-wide monitoring program. Groundwater levels should be measured monthly with groundwater quality sampling and testing conducted quarterly. 


\subsection{Closure considerations}

The slope rehabilitation is illustrated in Figure 8. Once tailings placement has been completed on the DSTSF, the top surface of the tailings will be graded to fall to drains in natural ground. The top of the stacks will be covered by soil, mine waste and mulched vegetation. The need for a liner to minimise infiltration into the dry stack will be assessed from the data obtained from the instrumentation. The thickness of the cover system will also be determined based on the instrumentation which will indicate the success or otherwise of the intermediate LDPE layers and drainage in terms of production of any acid mine drainage. The final cover thickness will also need to consider the proposed end land use.

At final closure, the underdrainage and base drainage systems will be left open in order to ensure a phreatic surface doesn't build up within the stack leading to instability. Airlock systems can be incorporated into the stack toe bund to allow for water removal and prevent air entry into the drains, minimising air entry to the base of the stack.

At decommissioning of the DSTSFs, all conveyors, pipework and pumps will be removed, and access roads and other infrastructure rehabilitated.

Closure of the DSTSF will need to cater for sulphide oxidation. Technical investigations to facilitate TSF closure design need to be undertaken well in advance of decommissioning.

\section{Conclusion}

The studies undertaken to date, as discussed within this paper, demonstrate that dry stacking is feasible for the Mahenge Graphite Project and offers a number of significant environmental benefits. The conceptual dry stack design presented shows two dry stacks in valleys near the Ulanzi process plant. The dry stack concept has a reduced footprint compared to wet tailings storage alternatives.

At this stage, the design is conceptual and a number of additional studies are required to develop a detailed design. These studies, scheduled to commence in early 2019, include detailed geotechnical site investigations and testing, additional tailings characterisation, hydrology and hydraulics of the stack, seismicity of the project area and further consideration of the design details of the stack.

\section{Acknowledgement}

The assistance and contributions from colleagues in the various organisations working on the Mahenge Project in the execution of the preliminary assessment and contribution to the preparation of this paper are gratefully acknowledged.

\section{References}

Australian National Committee on Large Dams 2012, Guidelines on Tailings Dams Planning, Design, Construction, Operation and Closure, Australian National Committee on Large Dams, Hobart.

Lubkowski, L, Villani, M, Coates, K, Jirouskova, N \& Willis, M 2014, 'Seismic design considerations for East Africa', Proceedings of the Second European Conference on Earthquake Engineering and Seismology, European Association for Earthquake Engineering, Istanbul, pp. 201-212.

Terzaghi, K \& Peck, R 1967, Soil Mechanics in Engineering Practice, 2nd edn, John Wiley \& Sons, New York.

United Republic of Tanzania 2013, Tanzanian Regulations - Water Resources Management (Dam Safety) Regulations, GN 237, dated 2 August 2013, United Republic of Tanzania. 